\section{Francis Crick (8th June 1916 - 28th July 2004)}

On 25th April 1953, there appeared three papers in Nature which changed our view of the world. The structure of the DNA double helix, with its complementary base pairing, is one of the greatest discoveries in biology in the 20th Century. It was also most dramatic, as, quite unexpectedly, the structure itself pointed to the way in which a DNA molecule might replicate itself, and hence revealed the "secret of life". The structure was solved in the Cavendish Laboratory, Cambridge, by Francis Crick and James Watson, using X-ray diffraction data that Rosalind Franklin, at King's College London, obtained from fibres of DNA.

I have elsewhere (J. Mol. Biol. 335, 3-28; 2004) told the story of how this came to happen: the origin of the research on DNA; the early investigations by Maurice Wilkins at King's College; the sorting out of the two forms of DNA by Franklin; the mistakes made both by Franklin and Watson and Crick; the intervention of old rivalries from an earlier generation (that of Lawrence Bragg and Linus Pauling); and the final model-building by Watson and Crick to give the three dimensional structure.

The structure was instantly accepted by the discerning few, but it's reception was mostly hesitant, and had to await confirmation through biochemistry by Arthur Kornberg and through X-ray crystallography at King's College by Wilkins' group. Yet, even then, this remained a discovery in chemistry, until the biological principle of "semi-conservative" replication, proposed by Watson and Crick, was proved by Messelson and Stahl in 1958.

The key points of the paper may be summarized as follows. Within the DNA structure, the two chains, held together by hydrogen bonding between the specific base pairs A-T and G-C, were seen to bear a complementary relationship to each other. This means, as Watson and Crick spelt out in their second paper in Nature in May 1953, that when the two chains come apart during replication of DNA, each can be used as a template to assemble a duplicate of its former partner. The crucial feature of the structure of DNA is not therefore the actual double helical form of the two phosphate-sugar chains - eye-catching as it is - but the unique pairing of the bases projecting from each strand. Moreover, the base pairs can be fitted into the double helix either way round, so that all four bases can occur on both chains. Thus, the second Nature paper also contains the first clear statement on the genetic code: "It follows that in a long [DNA] molecule many different permutations are possible, and it therefore seems likely that precise sequence of bases is the code which carries the genetical information".

In 1962, the Nobel Prize for Physiology and Medicine was awarded to Crick, Watson and Wilkins. Rosalind Franklin had died in 1958, so the Nobel Committee were spared the difficulty required by their statutes of limiting the prize to a maximum of three people. The citation reads "for the discoveries concerning the molecular structure of nucleic acids and its significance for information transfer in living material." Note the word "information", a term that had never appeared in the writings of biochemists, who had been primarily concerned with the transfer of 'energy' in biochemical reactions. Indeed, the citation may be said to have looked forward to the genetic code, research on which was well under way by then, largely led and spurred on by Crick

Francis Crick was born in Northampton, educated at the Grammar School and later, with a scholarship, at Mill Hill School, London. He studied Physics at University College London and then stayed on to do a PhD. This was interrupted by the Second World

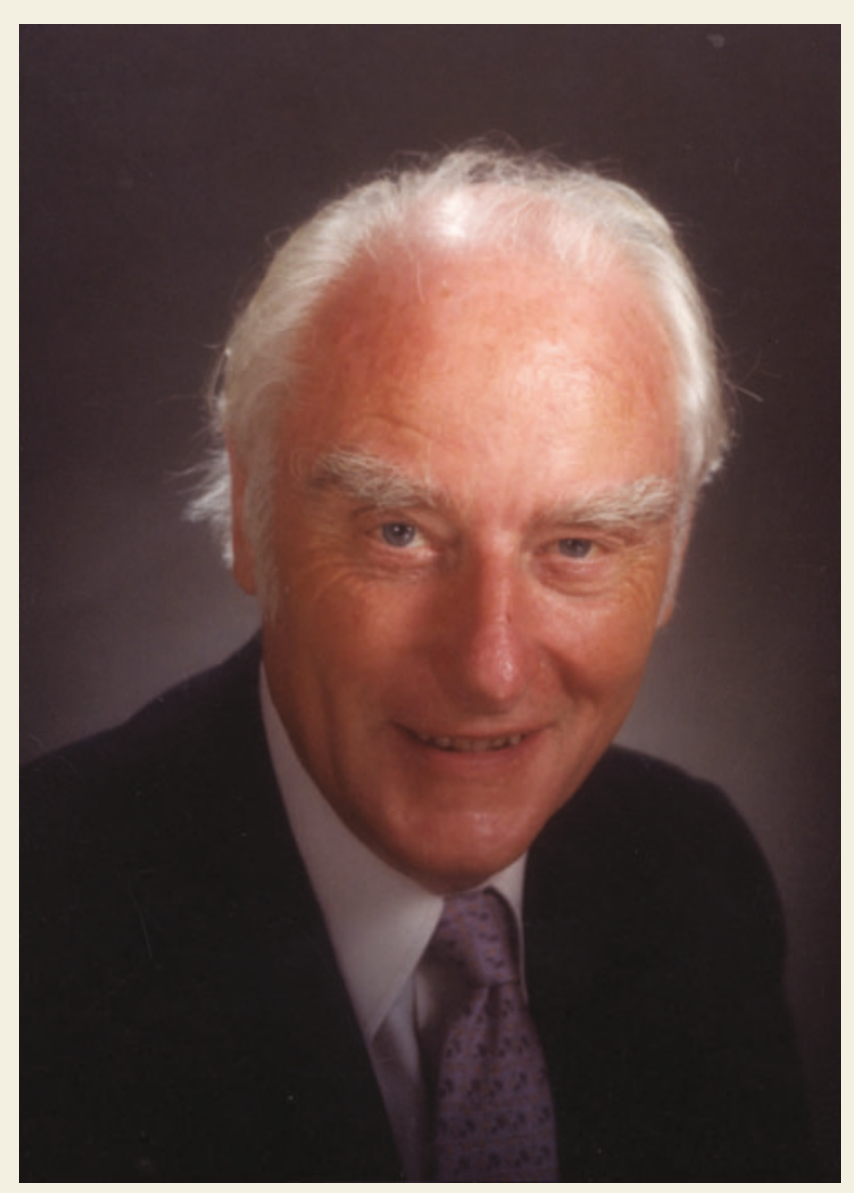

Credit: Kent Schnoeker / The Salk Institute

War, during which he worked in the Admiralty to design magnetic and acoustic mines that could be recognised by one's own side but not by the enemy. Until then he had shown little of his intellectual power, but something special about him must have been discerned by his scientific contacts at the Admiralty. They helped him to obtain a Medical Research Council (MRC) grant to start research in 1947 at the Strangeways Laboratory in Cambridge on the viscosity of cytoplasm, a subject which was meant to introduce him to biology - a field he had now decided to enter. From there he found his way in 1949 to the MRC Unit for the Study of the Molecular Structure of Biological Systems in the Cavendish Laboratory, and enrolled as a research student of Max Perutz to study ox haemoglobin. He got diverted rather easily from this thesis work by the arrival in the laboratory of James Watson, who had come there to learn X-ray crystallography so that he could eventually go on to study the structure of DNA. The two found each other like-minded about the importance of DNA, but their first attempt to build a model of DNA ended in fiasco. Franklin, in a colloquium at King's College in November 1951, which Watson attended, had put forward her view that the molecular structure was likely to be a helical bundle of two or three chains, with the phosphate groups on the outside, in contact with water and sodium ions. Watson and Crick's model was of three helical chains with the phosphates on the inside, neutralized by cations, with the bases pointing outwards. It turned out that Watson, not understanding the relationship between a unit cell of a crystal and the asymmetric unit, had conveyed the wrong water content to Crick. Crick redeemed himself by working out the theory of X-ray diffraction 
by a helical structure; he initially applied this to synthetic $\alpha$-helical polypeptides, but it later was equally applicable to DNA.

Although the name of Crick will forever be primarily associated with DNA, he continued to make several important contributions to X-ray protein analysis and protein structure right through the heyday of the search for the genetic code. With David Blow, he put Perutz's isomorphous replacement method for solving protein structure on a sound quantitative basis, taking account of experimental errors, to become a standard method. He solved the structure of $\alpha$-keratin, the prototype fibrous protein, and showed that it consisted of two Pauling $\alpha$-helices slightly deformed to coil round each other - the "coiled coil". He arrived at this by a brilliant simplification in which the "knobs" (protruding amino acid residues) from one helix fit into the "holes" surrounding the knobs on the other and, to boot, derived theoretically the complicated diffraction pattern to be expected. A foray into collagen structure, inviting mock scorn from Watson, with Alex Rich revealed a triple coiled-coil and pointed the way to a complete solution by G. N. Ramachandran.

All through this time Crick was thinking about the genetic code. How does the information carried by the sequence of bases in a DNA molecule finally get transferred into the sequence of amino acids in a protein? While others looked for a direct physical relationship between a DNA sequence in the helix and an amino acid, Crick reasoned that there had to be an 'adaptor' molecule which carried an amino acid to line up on the RNA sequence translated from the DNA. Moreover, this was likely to be a nucleic acid that recognized the particular codeword on the RNA by the same kind of base pairing as was found in the double helix. Finally, in 1957, Crick identified the adaptor as a small soluble RNA recently discovered by Hoagland, later called transfer RNA, as it transfers an amino acid to the growing peptide chain.

This feat of the imagination exemplified Crick at the height of his powers, as does a brilliantly original paper with Sydney Brenner and Alice Orgel in Nature in 1961, entitled "The general nature of the genetic code for proteins". Brenner and Orgel had been trying to get at the code by mutagenising DNA with acridine and found that it could respond in two ways, either by changing one base into another or by inserting an extra base. But combinations of mutations produced puzzling results, which Crick showed could be explained if, and only if, the codeword (or codon) for an amino acid consisted of three bases. Eventually, all 64 codons were worked out in detail by biochemists using cell-free protein synthesis.

During this period of the 50s and 60s, Crick became, as it were, the conscience of the new subject of molecular biology, spanning as he did its two main components, macromolecular structure (and function) and molecular genetics. He led, he inspired, he conducted an extensive correspondence, he corrected mistakes, settled disputes, he cajoled, he joked. He was generous with his ideas, with his suggestions, and almost always courteous, but could be quite fierce when he encountered muddled thinking and sloppy experimentation. By the 1970s, Crick saw that it was time to move on to problems in cell biology. He and Brenner recruited, among others, John Gurdon and Peter Lawrence, and changed the name of their Division of Molecular Genetics to Cell Biology. Thus, two other animals, Xenopus laevis and Drosophila melanogaster, were introduced into the laboratory, to complement the nematode, Caenorhabditis elegans, already under study by Brenner.

Crick was often described as a theoretician, but this misses the whole man. He understood experiments, he did some himself; for example, trying to demonstrate base pairing between isolated bases, or extracting ribosomes to try out some ideas on protein synthesis. When we worked on chromatin, he would concentrate for hours on end, reading tedious detail in the literature to capture a possible clue. Later, he mastered much neuro-anatomical detail, which elicited the respect of the experts in the field.

Over the years, I learned from him, as he once wrote about himself and Bragg, from watching how he went about a problem. In fact I owe him a particular debt for suggesting that I might take up the subject of chromatin, which he regarded as ripe for study, having heard that there were not twenty or so kinds of histones, the molecules that package DNA, but only five, all the rest being chemical modifications of the parent proteins. This eventually led in our laboratory to Kornberg's discovery of the nucleosome, our work on its structure and on the higher order folding of chromatin.

This loose collaboration came to an end in 1976 when Francis, at the age of 60 , decided to move to the Salk Institute to take up a new field - neuroscience. This did not come as a total surprise, because as early as 1962 I remember Francis talking excitedly about Hubel and Wiesel's paper on cortical neurons that responded to the directionality of lines and edges. At the Salk Institute he was a force in building up neuroscience at various levels, but particularly in the field of vision, because Crick thought that this would be the easiest path to understanding consciousness (his ultimate goal) but, for practical purposes, reduced to "awareness": are there awareness neurons? His book of 1994, The Astonishing Hypothesis, set out his ideas and arguments that consciousness is now accessible to scientific investigation. The book is dedicated to Christof Koch of CalTech, with whom he continued to collaborate in setting out a framework for the research.

A new book by Koch, The Quest for Consciousness, appeared a few months ago, the result of many years of thought and interpretation. When, in speaking to Francis, I called it "your book", he corrected me courteously "Christof's book; our work". Francis fought a long battle with cancer, pursuing his subject to the end. He died in hospital three hours after he finished preparing the manuscript of a paper. It is hard to believe that that penetrating intellect and powerful personality has been extinguished. But he will be remembered as one of a select few who created a new science, and his name is likely to live in biology with that of Darwin.

AARON KLUG

MRC Laboratory of Molecular Biology, Hills Road, Cambridge, CB2 2QH, UK. 